\title{
Lithosphere as a Nonlinear System: Geodynamic Consequences
}

\author{
E. G. Mirlin \\ Vernadsky State Geological Museum, Russian Academy of Sciences \\ Russia
}

\section{Introduction}

\subsection{Nonlinear geological medium: theoretical aspect}

The deterministic viewpoint for natural evolution was dominant in natural sciences for long time. This relates in full measure to geodynamics, and it seems that plate tectonics, being a basis for modern geodynamic conceptions for over 30 years, confirms such viewpoint. The plate tectonics, as a bottom of fact, presents a purely mechanical model based on a simple geometrical observation: the similarity of contours of continents gathered around the Atlantic Ocean. Formerly they composed a single whole, which was broken up and slid apart, to a first approximation, keeping their primary contours. Under this point of view it is meant that geologists deal with the geological environment, being a continuous monolith composed of various solid rocks. This monolith is mechanically divided into different in size fragments (a separate question is a cause of this fragmentation), and the task of tectonic geologists is just to collect the fragments, using their outlines, to reconstruct the history of continents' movements and development of the oceans and fold belts, and to forecast their further evolution. The plate-tectonic prognosis is taken to be sufficiently determined by the regularities of plate kinematics.

The progress of plate tectonics in explanations of many phenomena of the lithosphere structure is obvious, but the question is: what paradigm is going to take its place? This question is even more so appropriate as in the latest quarter of the 20th century the philosophic and methodological conceptions in the field of natural sciences changed from determinism to instability. Works by I. Prigozhin played a great role in the process. The basis of his "philosophy of instability» is dualism [1], stability and instability existing in the universe at the same time. The core of such perception is a thesis about development of highly organized structures in the conditions of nonequilibrium and nonlinear processes in different natural mediums $[2,3,4]$. Nearly three decades have passed since the appearance of instability philosophy, but it is obvious that the introduction of new ideas to geology goes rather slowly. At the same time, during the last two decades of the 20th century, i.e. practically simultaneously with the invention of this new philosophic conception, geophysicists (first of all, seismologists) carried out both experimental and theoretical investigations demonstrated that the medium, with which specialists in the field of the solid Earth deal with, belongs to the mediums characterized by instability and nonlinearity $[5,6$, 7]. In essence, a crucially new view on rock characteristic and the whole lithosphere was established, in particular: 
- hierarchical heterogeneity all over the scale range, from small mineral grains to planetary-scale irregularities;

- physical nonlinearity appearing in the interdependency of physical processes;

- $\quad$ energy activity, i.e. the ability to permanently produce energy as seismic, acoustic, and electromagnetic emission, as well as heat;

- changeability of physical properties in time, as result of activity and physical nonlinearity; and

- ability of geophysical processes for interaction.

Due to the above-indicated characteristics, the medium acquires properties of fluid; and, with that, self-similar processes, producing structures adapted for the consummation of incoming energy, take place in the medium. The Earth as a whole and its spheres represent the open systems, which convey and transform incoming energy.

An important point of the nonlinear-geophysical-medium conception relates with the fact that the engine of many geodynamic processes (splitting, rising of earthquake sources, rocks' melting, and others) is energy of rocks, which can be released under one or other type of actions [8]. In other words, these processes present a response of the medium to stress, and the more the medium deviates from equilibrium, the stronger is the response. In accordance with the nonequilibrium thermodynamics, the energy balance of an open system composed of rocks will be governed by two opposite entropy flows: $d_{i}$ and $d_{e}$ [9]. The first one depends on irreversible processes inside the system (as applied to rocks, the interatomic bond breakage in a crystal lattice) and the second one, on the energy exchange between the system and the environment. Under the low destruction speed, the system can be characterized by relatively stable conditions, under which $d_{i}=-d_{e}$, i.e. the entropy doesn't practically change with time. The most interesting and important properties characterize the nonequilibrium systems, when $d_{i}>>d_{e}$, i.e. the entropy inside the system sufficiently exceeds its energy losses through the exchange with the environment. In that case the selforganization process in the system leads to the formation of so-called dissipative structures, which existence is supported only due to the dispersion (dissipation) of energy incoming from the outside.

The development of methodology to solve real problems of geodynamics on the basis of instability and nonlinearity, undoubtedly, faces a lot of difficulties, as we are dealing with nonlinear physical systems, which adequate description requires an extremely complex apparatus. In this regard, a relatively rapid progress of plate tectonics is demonstrative. In many ways, it became possible due to the fact that both the main idea (detachment of lithosphere into plates shifting relative to each other) and well-composed methodology (analysis of plate-movement characteristics, quantitative assessments of the oceaniclithosphere age, changes of submarine topography and geophysical fields with time, and etc.) appeared nearly at the same time. The problems, arising at the development of new methodological principles, are objective; therefore one wouldn't expect that the conception of nonlinearity would be so rapidly progressing as the paradigm of plate tectonics. Nevertheless, it is obvious that without its application the further progress in our understanding of nature of most geodynamic phenomenona becomes impossible.

In the last few years our efforts have been applied to the revelation of the data that could witness nonlinearity of lithosphere medium, as well as to interpretation of some geodynamic phenomenons in the context of a nonlinear medium. The goal of this article is to state (although in a condensed form) obtained results and to determine some of the problems appearing on the way. 


\section{Results and discussion}

\subsection{Fractal characteristics of geological mediums}

The most important evidence of geological medium being nonlinear and unstable and of the self-organization processes in the medium is an extremely wide range of geomorphological, tectonic, and petrologic objects characterized by dimensional invariance of structural geometry, in fact, fractal organization of the objects. It includes geometrical pattern of seismic delamination of the Earth [9], submarine topography [10,11], banks and channels of rivers [12], seismicity [13], fault systems and grains in rocks [14], lithospheric plates and blocks of various ranks [15], etc. These objects are quantitatively characterized by fractal dimension; furthermore, in many cases the scale self-similarity of structures is distinctly obvious under qualitative, phenomenological treatment. We would like to illustrate this by the most striking examples.

One of the most interesting in this regard objects is the Sea of Marmara basin, which recently has been the subject of comprehensive systematic investigations [16, 17]. A continental structural type characterizes the Earth's crust of the basin, and peculiar properties of its structure and evolution allow us to take it as an analogue of the early stage of continental breakup. The total opening amplitude nearby the Sea of Marmara reaches 100 $\mathrm{km}$ evidenced by from satellite geodetic measurements. The basin shape is an irregular rhomb, which allows us to characterize it as pull-apart, trans-displacement stretching structures (Fig.1a). A considerable thickness of the Quaternary sediments (on average 1-2 $\mathrm{km}$ up to $6 \mathrm{~km}$ in the northernmost and deepest depression) confirms that the structural depression of the Sea of Marmara was formed as a result of diagonal stretching.

Under more detailed investigations, it occurs that both branches, the North Anatolian and South Anatolian strike-slips, limiting a main pull-apart depression, are not uninterrupted and united. They also split along both diagonal and oblique faults regarding a general strike, into segments different in rank; each of the segments comprises rhomboid or oval in plane pull-apart depression smaller in size than a main basin. The nature of these structures is determined not only by general geometry, but by the analysis of morphotectonics of their edges, as well as by characteristics of layers' displacement within sedimentary series. The depression's slopes complicated by numerous benches (scarps) divided by inclined faults evidence their formation as result of diagonal stretching. Also, the depressions' flat bottoms are at 20-60 m deeper than the surface of the surrounding bottom. A major geometrical parameter of such depressions, a width between opposite sides, varies roughly within one order, from $10 \mathrm{~km}$ to $100 \mathrm{~km}$.

Inside the Central Basin about $37 \mathrm{~km}$ wide (fig.1b-1c), a small rhomboid depression was discovered using side-looking sonar and seismic profiling. It is limited by numerous echeloned normal faults. The distance between opposite sides of this depression is not more than $10 \mathrm{~km}$ (fig.1d). Folded sediments both to the east and west from the depression can indicate compression, which is an important component of geodynamic settings.

Thus, analysis of available data, describing structure of the basin of Sea of Marmara in spread-spectrum scales, clearly shows scale invariance of pull-apart depressions, and indicates fractal divisibility of the Earth's crust. Structural depressions of various scales occurred in connection with horizontal tectonic displacements along strike-slips are widespread in the Earth's crust. In most cases they have a scale-invariant rhomb shape in plane [18]. So, different in rank pull-apart depressions in the Sea of Marmara have engaged our attention by their structural-geometry similarity to rhomb- and wedge-like depressions 


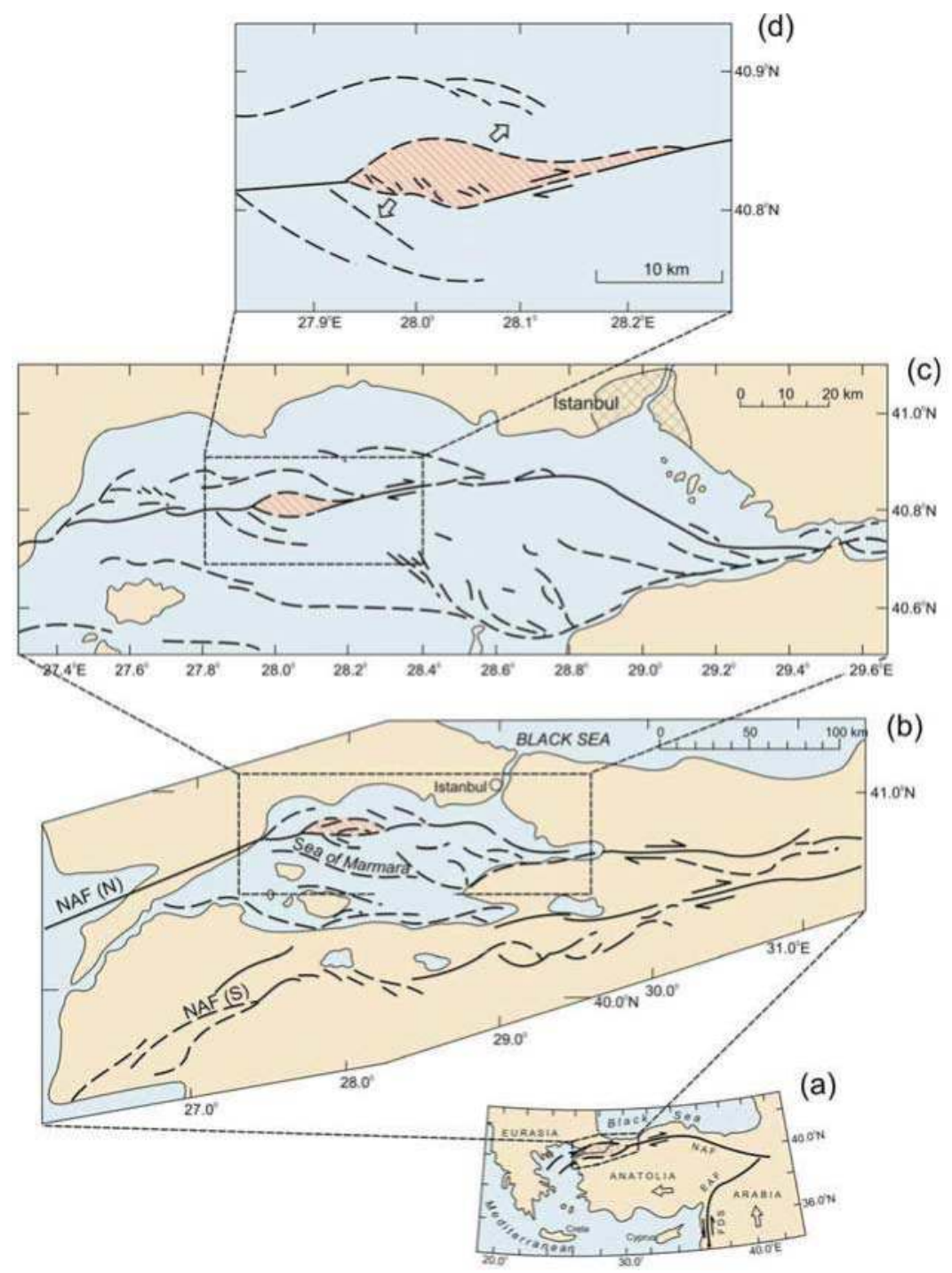

Fig. 1. Fractal structuring by the example of scale-invariant pull-apart structures of the Sea of Marmara and its framing after [16]. (a-d) sequential scale extension: (a) splitting of the North Anatolian Fault - NAF(N) and NAF (S) dividing the Anatolia Microplate from the Eurasian Plate. (FDS) Fault of the Dead Sea, Arrows show moving directions of plates and displacements along faults. (b) pull-apart basin of Sea of Marmara and different in rank rhomb-like or oval pull-apart structures along $(\mathrm{N})$ northern and $(\mathrm{S})$ southern branches of the North Anatolian Fault. Solid and dotted lines indicate main and general faults accordingly; and arrows, displacements along faults. (c) pull-apart structures of the northern branch; (d) one of rhomb-like local young depressions; arrows show displacements along the fault and the direction of the depression's opening. 


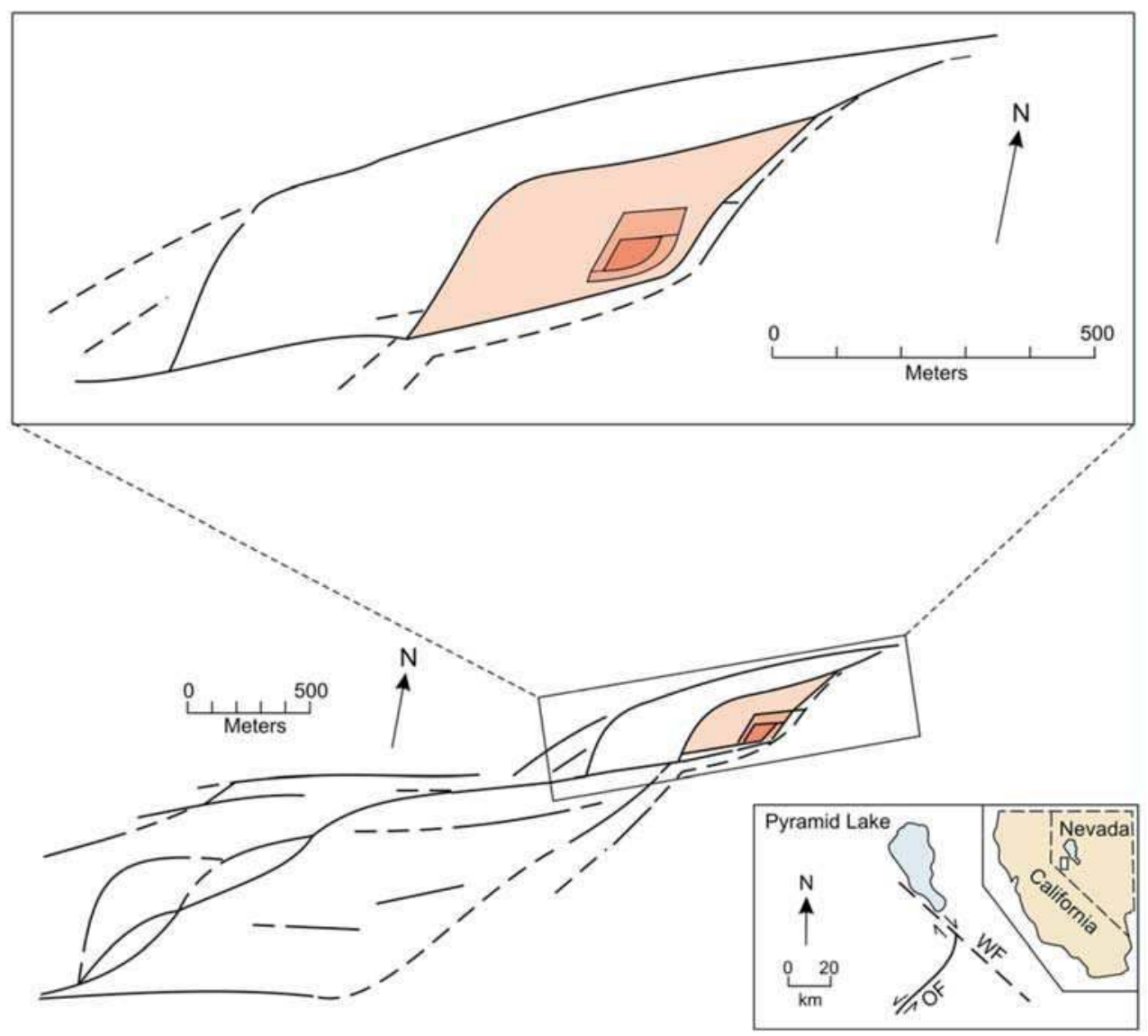

Fig. 2. Fractal structurisation by the example of scale-invariant pull-apart depressions along the fault, left-side slip-strike Olinghouse in western Nevada (USA), which location is indicated in the insert. Thicker hatching indicates deeper depressions. (WF) Walker Fault, (OF) Olinghouse Fault after [18].

originally connected with the Olinghouse strike-slip (Basin and Range Province in the western Nevada in the border with California). These depressions are as if nested one inside the other (fig.2), and their bottoms are dipped tens of meters beneath the adjacent surface [19]. Although the depressions have some differences in regional geodynamic settings, the Earth's crust structure, and depressions' sizes (they are rather smaller in Basin and Range Province than in the Sea of Marmara), they are similar in geometry and genesis, i.e. both examples demonstrate clear signs of structural self-similarity.

The next demonstrative example of scale isomorphism is related to spreading zones at the crests of the mid-oceanic ridges (MOR). A distinguishing characteristic of their structural geometry is segmentation different in rank, which itself indicates that the lithosphere is highly fractional, and for this reason the crests are good subjects for revelation of fractal structure formation. Echeloned in plan and various in rank geometry of spreading centers 
(a)
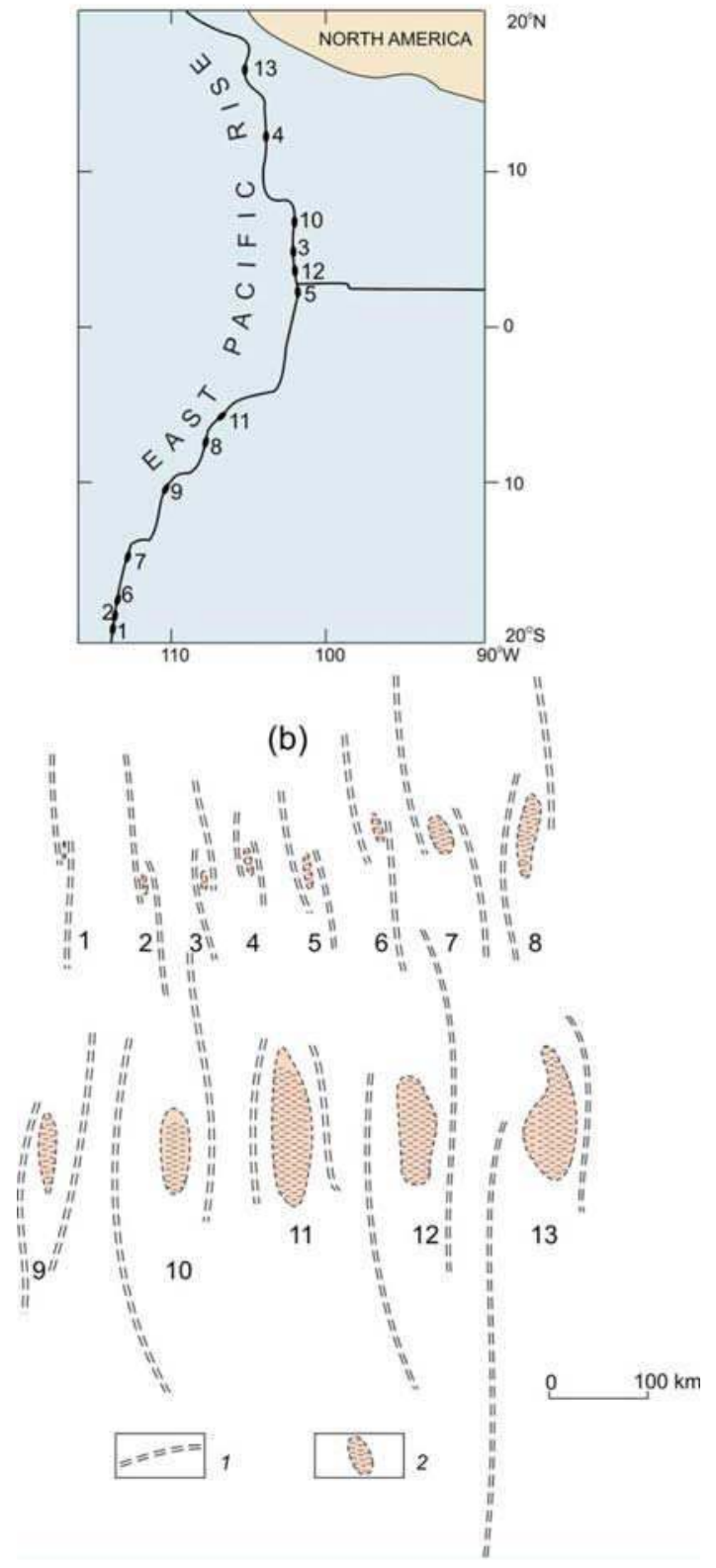

Fig. 3. Geometric self-similarity of overlapping spreading centres (OSC) at the ridge of the East Pacific Rise: (a) OSC locations; (b) their generalized morphotectonic schemes, based on comprehensive investigation of the submarine topography. (1) axes of spreading centers, (2) structural depressions between them, after [29]. 
indicates the presence of a shear component along the practically full length of the MOR global system. The strike vector is oriented at different angles to the crests in the different sections of the ridge. In other words, in terms of geodynamics, the MOR crests present spreading zones with a shear component. The difference in the segments' geometry of slower and fast MOR is connected with the lithosphere plasticity, which depends of the lithospheric temperature regime, and, thus, geometry of spreading centers indicate the accretion regime of the Earth's crust [20].

Their structural-geometrical isomorphism can be clearly shown by the example of MOR crests with intermediate and high velocities $(4-8 \mathrm{~cm} /$ year, $8-12 \mathrm{~cm} /$ year and more, accordingly). In such ridges, overlapping spreading centers (OSC) varied in size are widely known; most of them are mapped with high-resolution echo depth-sounders. The OSC geometry is quite simple and can be the subject of comparative studies. For this purpose, we analyzed bathymetry of 13 mapped in detail different in scale OSCs located at the East Pacific Rise (EPR) crest between $16^{\circ} \mathrm{N}$ and $20^{\circ} \mathrm{S}$ (fig.3a). Morphotectonic maps of these structures were built, and then simplified into easy-to-use general schemes for the comparison in a unified scale (fig.3b). In addition to echelon-like displaced spreading centers, the schemes show structural depressions, appearing as troughs elongated concordantly to the crest trend. Some variations in the OSC geometry are observed, but they are secondary in comparison with the indicated above general features.

Spreading velocities in the observed EPR segment vary from $9 \mathrm{~cm} /$ year to $16.2 \mathrm{~cm} /$ year, however a clear connection between morphometric parameters of OSC and velocities of the bottom growth has not been established. The most essential property of the observed structures is their geometrical self-similarity. The length of the shortest depression is about $15 \mathrm{~km}$, and the longest one is $130 \mathrm{~km}$, the length of the axis-rift segments limited by adjacent overlaps ranges from lesser than $15 \mathrm{~km}$ to more than $200 \mathrm{~km}$, a relative depth of these depressions is first tens of meters for small overlaps and first hundreds of meters for large ones. In other words, quantitative adjectives change practically an order with constant geometry of these bottom forms, which makes a clear evidence for structural-geometrical isomorfism.

\subsection{Vortex movements at the oceanic opening}

Vortex structures and movements, accompanying the oceans' genesis, are the next important evidence for the nonlinearity of lithosphere medium. It is common knowledge that vortex movements various in rank are an essential feature of dynamics of the Earth's outer covers, atmosphere and hydrosphere, for which general features are instability and nonlinearity. For this reason we will pay more attention to the characteristics of vortex structures, as well as to possible nature of such movements.

As stated above, this medium has a block-hierarchical structure in every space-time scale, it is nonlinear, and energetically active, which provides the medium with properties of flowing fluid clouds; formation of vortex movements becomes high-probable and actual observations of the oceanic basins' evolution confirm that [21, 22]. Above all, this is the evolution of their structural geometry. It is characterized by two peculiarities: propagating of the spreading axis and its whirling. We can demonstrate this at the example of the North Atlantic, which is one of the well-studied areas of the World Ocean. The propagating of the spreading axes from the south (equatorial zone) to the north is clearly traced in its evolution since the Late Jurassic. In the Early Cretaceous (120 Ma) this propagating lasted that resulted 
in opening of the North Atlantic to the north of the Azores. However, this opening was complicated by the fact that secondary branches detached off a main opening trunk, were dying with time. Among such branches are the Rockall Trough, the Bay of Biscay, for which the opening was accompanied by rotation, the Iberian Peninsula, Basin of the Labrador Sea, as well as Porcupine and Baffin basins (fig. 4 a). By $90 \mathrm{Ma}$, the stretching had most likely stopped in the Bay of Biscay, Rockall Trough, and Porcupine Basin, but it continued in the Labrador Sea and presumably in the Baffin Basin (fig. 4b).
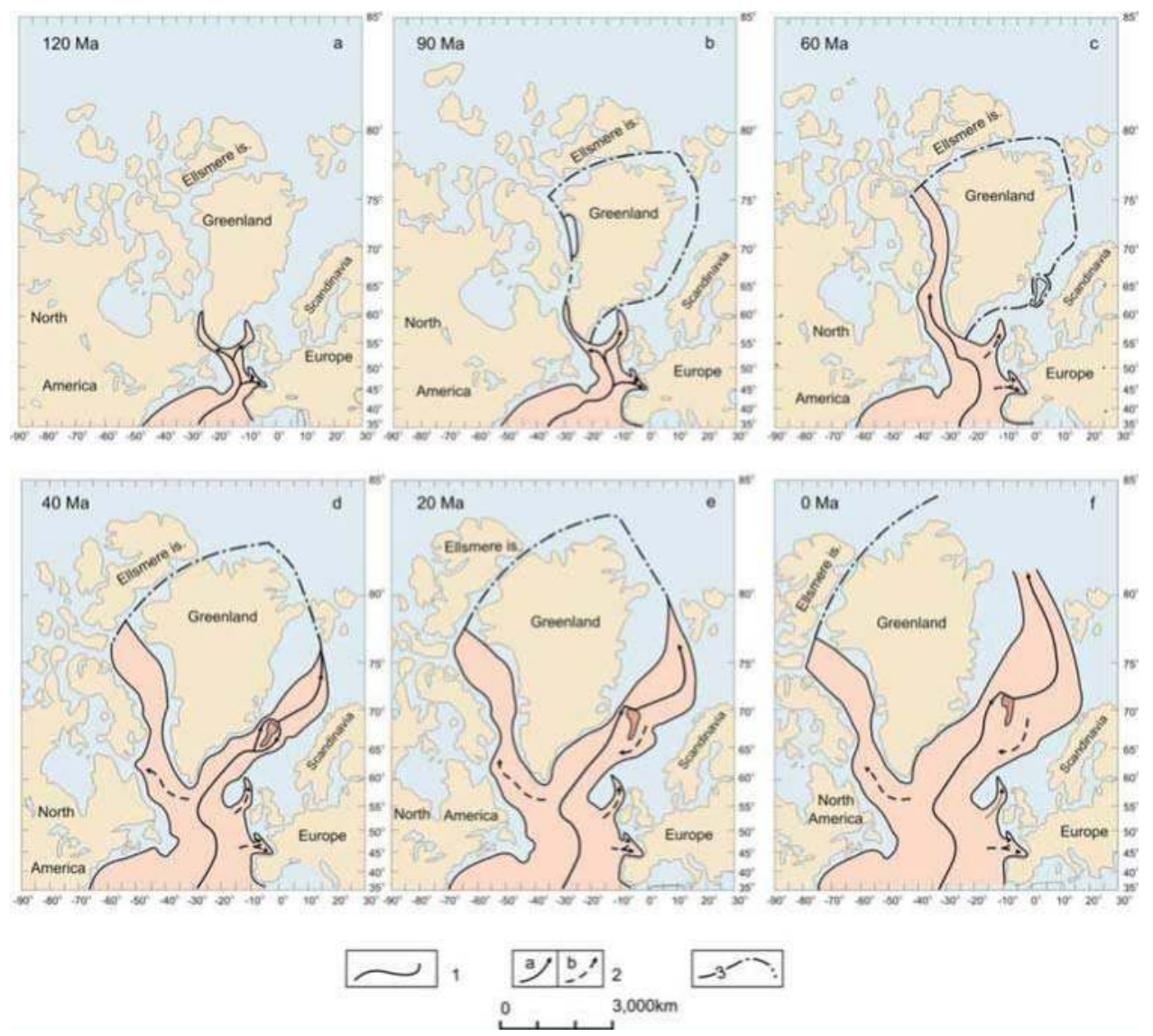

Fig. 4. Development of vortical spreading systems of the North Atlantic as determined from paleogeodynamic reconstructions $[22,39]$. Time windows are shown in the figure. (1) Continental margin; (2) direction of spreading axis propagation: (a) active, (b) extinct; (3) line of initial opening of the ocean.

It is of interest that the separation of Greenland from Eurasia started about $60 \mathrm{Ma}$ along not having existed by that time continental rifts, but noticeably to the west, along the axis of the mid-oceanic ridges of Reykjanes, Kolbeinsey, and Mona. At the same time spreading zones sprung to the southeast and northwest from the blocky Jan Mayen Ridge, which stayed apart and formed an independent, small in size continental lithosphere plate (fig. 4c). 
By $40 \mathrm{Ma}$, the process of the oceanic formation had ended in the Labrador Sea and Baffin Basin and a general tendency to propagate the oceanic formation extended to the north as result of the separating Greenland from Eurasia. As before, the spreading axis propagating was not simple. In this case it was complicated by the presence of the Jan Mayen Microplate, as well as its rotation anticlockwise round a pole located in immediate proximity of Jan Mayen Island. This rotation was accompanied by the formation of two vortex-like spreading systems. With that, the northwest system propagated roughly in parallel with the general direction of the spreading axis of the North Atlantic, i.e. roughly to the north, and the development of the southeast branch (in the Norwegian Basin) is characterized by the propagating oriented about toward the North Atlantic system (fig. 4d).

At a period of $40-20 \mathrm{Ma}$, the Knipovich mid-oceanic ridge arose in the area of Spitsbergen Strike-Slip Zone as a result of the opening-axis propagating to the north. Due to the development of the above-mentioned MOR, a tendency of twisting the advancing opening general-zone of North Atlantic, which appeared at the previous stage, came to the accomplishment (fig.4e). Finally, the present structure of the North Atlantic (fig. 4f) clearly demonstrates results of the above-examined evolution: the development of the general spreading zone, as well as of the secondary branches, includes both propagating and simultaneous whirling. Because of this, the oceanic basin is not unified, but is constituted by the system of vortex-like depressions variable in size and age and having independent spreading systems. Accordingly, besides of large continental blocks of Eurasia, North America, and Greenland, there is a whole set of microcontinents and elevated blocks with subcontinental crust (Jan Mayen, Hatton, Rockall, etc.).

The above-considered basic tendencies in the North Atlantic evolution, propagating of the axis and their whirling, are known in the other spreading basins of the world ocean. At that, a size range of vortex systems is extremely wide. For example, at the EPR crest, which shape demonstrates a vortex $7.000 \mathrm{~km}$ long, there are microplates of Juan Fernandez and Easter Island, framed by pronounced vortex-like spreading zones with a length of $300-500 \mathrm{~km}$ (fig. 5). Their boundaries are presented as pseudo-faults formed with the propagating of spreading axis. Overlapping spreading centers at the EPR crest can be assign to vortex structures as well, as they show signs of vortex whirling in the propagating of spreading axis. In the Indian Ocean, the rift of Tadjoura together with the spreading zone of the Gulf of Aden and Arabian-Indian and Central Indian MORs presents a giant vortex about $8.000-\mathrm{km}$ long, as if intruding into the continent of Africa. The tendency towards the vortex whirling of the West Indian MOR is clearly seen near the Rodriguez triple junction. Many of back-arc basins in the Pacific Ocean-Asian continent transition zone formed as a result of stretching also present vortex-like spreading systems various in size. As a whole, quantitative characteristics of such structural systems in the world ocean can change more than two orders, in other words, vortexes are characterized by different scale self-similarity. Continental massifs evolved from the Pangea breakup differ in size more than two orders as well; also, in detail studies microcontinents in their turn can be divided into individual blocks still smaller in size. Undoubtedly, the formation of self-similar elements during the lithosphere evolution presents an additional evidence for lithosphere to be considered as an open, nonlinear dynamic system, in which the processes of self-organization act [6] and where vortex movements of different scale may well be developed. This is also supported by the instability of the ocean formation - the displacement of the opening axis with space and time. The latest probably reflects the instability of convection-current dynamics, which is a major condition for vortex generation. 


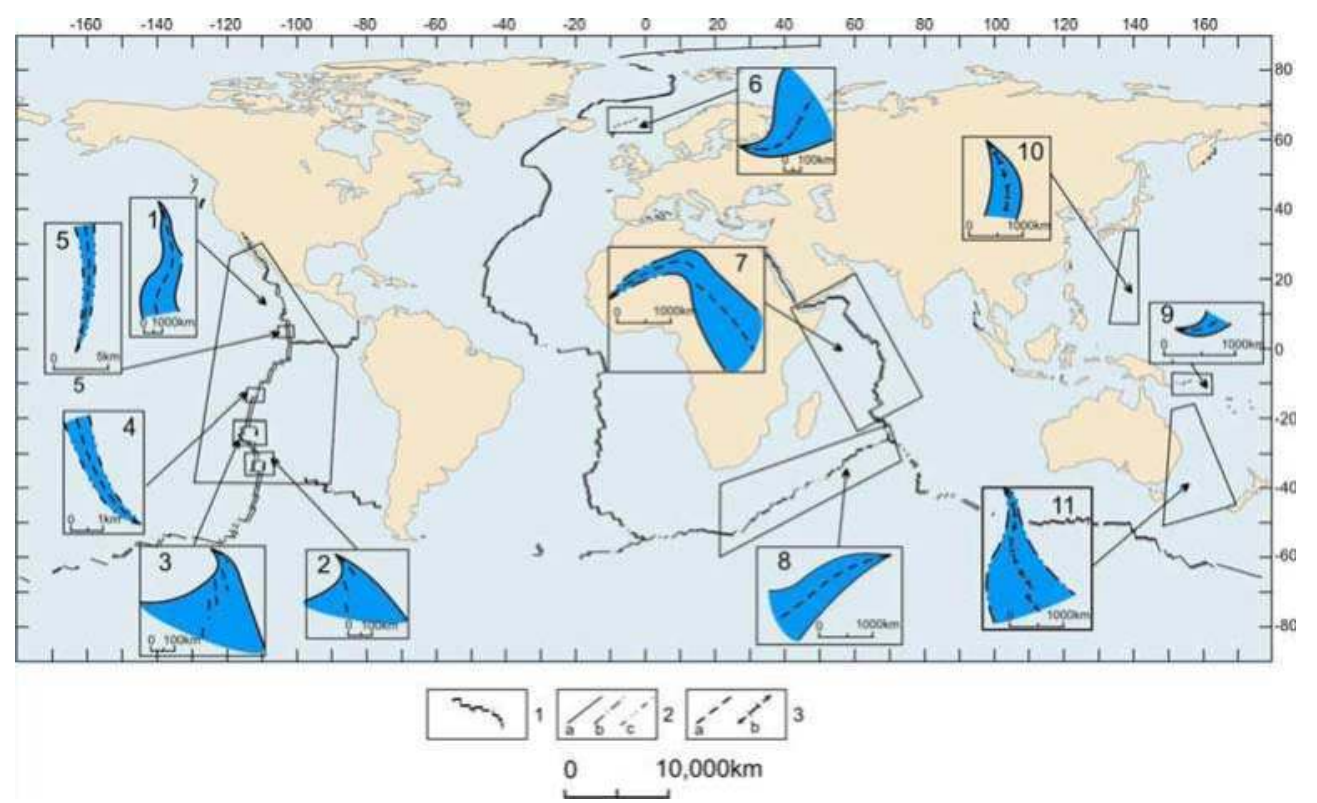

Fig. 5. Vortical systems in the World Ocean (numerals in figure): (1) East Pacific Rise (EPR); zones of microplate spreading: (2) Juan Fernandez; (3) Easter; branches of overlapping spreading axes at the EPR crest: (4) near 12055' S; (5) near 5030' N; (6) Norwegian Basin; (7) Tajura Trough, Gulf of Aden, and Central Indian Mid-Ocean Ridge; (8) West Indian MidOcean Ridge; transition zone from Pacific Ocean to Asian continent: (9) Solomon Depression; (10) Shikoku and Parece Vela Basins; (11) Tasman Sea.

(1) Axes of the mid-ocean ridges; (2) boundaries of vortical systems: (a) along the isochron lines of the oceanic crust and pseudofaults, (b) along the ocean/continent boundary, (c) along the foot of the central plateau at the EPR crest; (3) spreading axes: (a) active, (b) extinct.

\subsection{Vortex movements during the oceanic-basins' opening at the junction zone of Eurasia, Pacific, and Australia}

As forming the Pacific margin of Eurasia, stretching efforts acted at regular intervals during relatively brief time (on average about $20 \mathrm{Ma}$ ) and were concentrated within lengthy bandlike belts. Such periodicity appeared against the background of the successive migration of subduction zones (also intermittently) from Asiatic and Australian continents to the Pacific [23]. As result, since the Later Mesozoic to the present, marginal-continental volcanoplutonic belts different in age have been formed, as well as island arcs and marginal basins, altogether constituting the junction zone. Below we consider the spatially irregular variability of vortex-like spreading basins within this zone.

Within an active zone of the Eurasia junction, other oceanic basins are known besides the ones indicated at Fig. 5. Their opening is also characterized by the presence of a vortex component judging from their configuration in plane and from the structure of linear magnetic anomalies. Among these there are spreading zones of the West Philippines, Okinawa, the Mariana Trench, Caroline, North Fiji and South Fiji, Lau-Havre, CarolineManus, and, quite possibly, a row of others. They were developed under various 
geodynamic settings either in the immediate back region of island arcs in connection with their splitting or at a noticeable distance from subduction zones. Paleogeodynamic settings were reconstructed for some of marginal basins, and we discuss those of them, in which the vortex whirling phenomena appear most distinctly.

The vortex-like opening of the spreading basin generated at the Pacific-Australian plates' boundary to the west from New Zealand since Eocene is an exceptionally demonstrative example. In accordance with the names of adjacent oceanic basins, the authors of investigations devoted to this region [24] call it Tasman-Emerald Basin (TEB). Its evolutional scheme is based on combined tectonic analysis of both marine geophysical data and geological structure of South New Zealand Island.

The region under consideration covers the complex of underwater Macquarie Ridge and its extension on the island as Alpine Fault, underwater Campbell and Challenger plateaus, and deep Emerald and Tasman basins (inset in Fig.6). The latest ones are typical oceanic spreading basins, and, at the same time, a spreading zone of the Tasman Sea with the age of Later Cretaceous - Palaeocene is a branch of the Southwest Indian Mid Oceanic Ridge, like branches of spreading in the North Atlantic. Since Eocene (45 Ma), after spreading in the Tasman Sea ended, a new boundary between Australian lithospheric plate and Pacific one has been generated along the line separated earlier unified continent including Challenger and Campbell plateaus (Fig. 6). The fact that ophiolite belt of the Dan Ridge existed at that time in the south of Southern Island is fundamentally important. It is considered as an essential confirmation of relative motion between plates with the mentioned plateaus included to be not only spreading, but accompanied with whirling and compression in the area of the vortex closure. This is supported by the fact that the line of original opening was a broken saw tooth curve indicating the presence of a slide component at the early stage of plates' relative displacement, in accordance with a model of vortex kinematics.

For the next period (later Eocene-Oligocene; $30 \mathrm{Ma}$, fig. 6), formation of the Tauru overfault zone became a characteristic that can indicate the continuation of compression along with whirling. Moreover, a clearly echeloned structure of spreading zone was formed, which demonstrates the presence of a slide component during the basin opening. By the middle Miocene (15 Ma) both slide and shear components had become predominant, which was expressed by an abrupt change of transform faults' strikes, as well as by the appearance of a compression belt in the extreme north of the opening basin. This trend in the change of geodynamic settings lasted afterwards; as a result, at present the whole northern segment of the TEB axis zone is a compression belt (fig. $6 \mathrm{~d}$ ).

The other example of the vortex-systems' evolution relates with the Philippine Sea, where three extinct spreading centers are revealed: one, the most ancient, developed in Eocene, is located in the West Basin and two young centers (with Oligocene-Miocene age), in Shikoku and Parece Vela basins in the eastern part of the sea. The first one has the northwest-southeast strike and its evolution is divided into a row of stages with the gradual propagating of the spreading axis and the axis's whirling to the west-northwest. Figure 7 demonstrates both initial (a) and final (b) stages. At that, one can notice that at the final stage axes of linear magnetic anomalies are unconcordant in relation to the boundaries of the spreading basin and the axis of spreading after kinematics' change angularly cuts older one. This conforms to the location of oceanic-crust isochrones according to the above-considered kinematic scheme of vortex-like opening. As for Shikoku and Parece Vela basins, fan-shaped in plane even-aged systems of linear magnetic anomalies discovered in both are indicating the fact that the opening axis propagating was coming roughly towards each other [25]. 

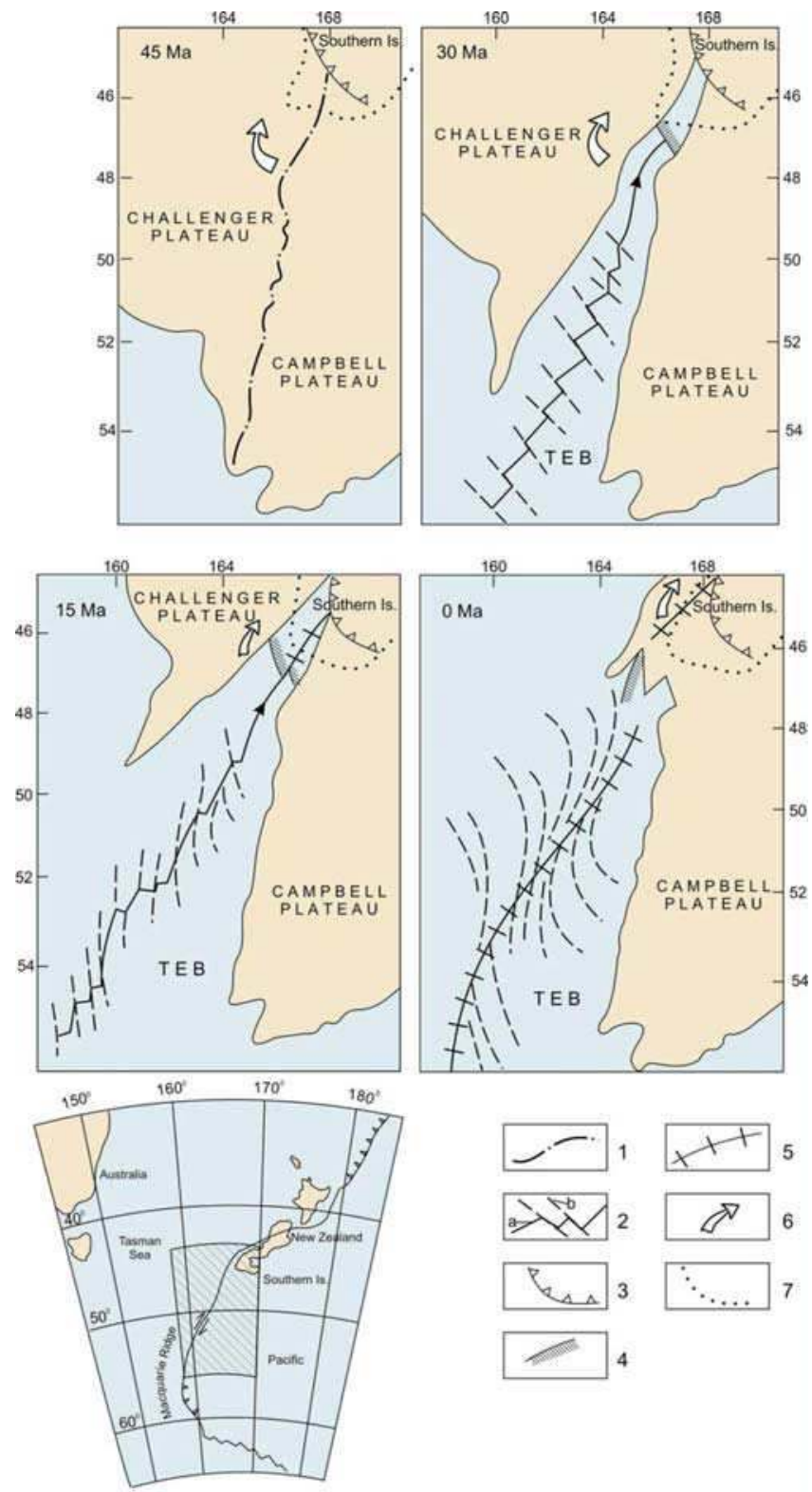

Fig. 6. Various time windows for the development of vortex-like spreading system of Tasman-Emerald Basin (TEB) after [24]. (1) a line of primary opening; (2) spreading axes (a) and transform faults (b), an arrow indicates the propagating direction; (3) ophiolite belt of Dan Ridge; (4) overfault zone; (5) compression belt, (6) direction of relative motion of Challenger Plateau relatively Campbell Plateau, (7) contours of Southeern Island. Hatching at the geographic scheme shows the position of the region under investigations. 

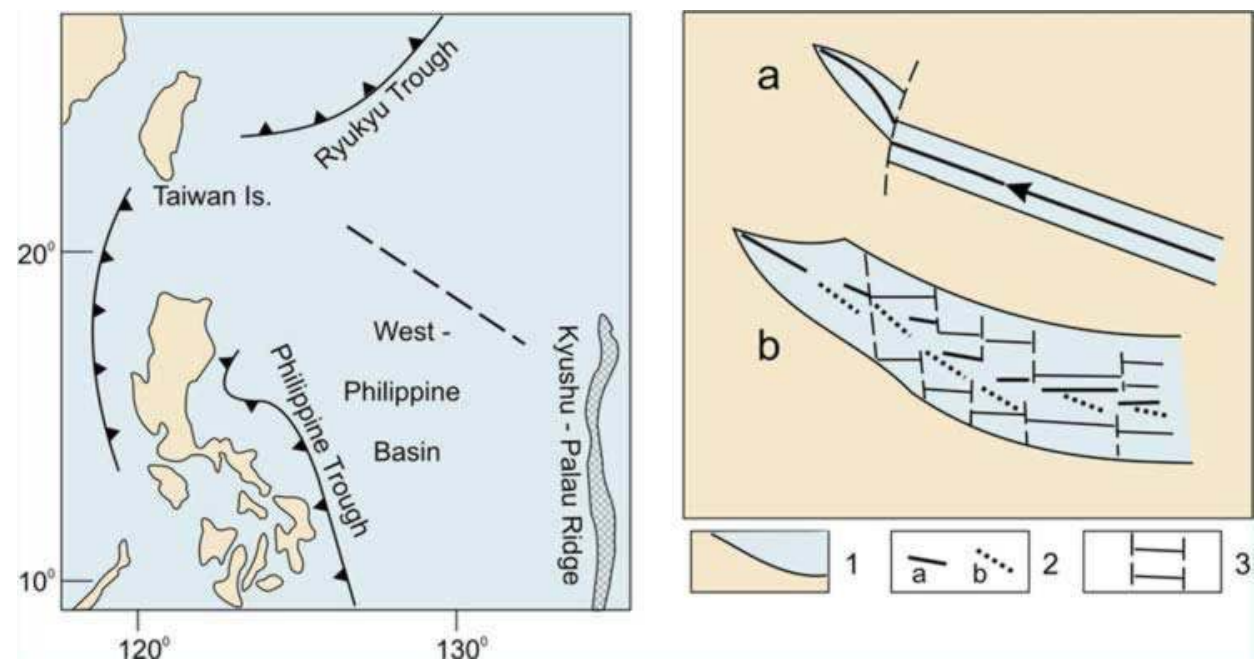

Fig. 7. The evolutionary stages of a vortex-like spreading system in the West Philippine Basin after [25]: (a) primary stage and (b) final stage. (1) boundary of the spreading system; (2) spreading axis: (a) before rebuilding, (b) after it; (3) axes of magnetic anomalies (solid lines) and transform faults (dotted lines). Hatching at the location scheme shows the position of the spreading zone.

The considered data witness to an important role played by the basins with vortex-like evolution in structure and development of the Pacific junction zone of Eurasia. At that, stretching belts, containing elements of these basins (subduction zones as well), show strong trend of migration from both Asian and Australian continents to Pacific, although isolated branches of non-contemporaneous stretching zones can be superimposed. Moreover, a doubtless connection is revealed between the spatial-temporal variability of stretching belts and age borders, corresponding to the change of kinematics of Eurasian, Pacific, and Kula lithospheric plates. The origin of new branches of vortex structures, which are sometimes characterized by opposite propagating of opening zones, are often confined to these age borders. This shows the similarity of evolution of the North Atlantic and stretching belts of the Pacific junction zone.

\subsection{Possible nature of vortical movements}

Essential difference in sizes of the oceanic vortex structures testifies that vortex motions are caused by dynamics of the Earth's covers essentially different in depth but with the same physical mechanism. Global vortexes (many thousands of $\mathrm{km}$ in size) can be resulted from the fact that at least some of the covers revolve around the central axis at a various speed and, consequently, move relatively each other. At present, most scientists are inclined to believe this idea, and it really looks probable, taking into consideration different physical specifications of the covers, especially, their integrated density and viscosity. If, for example, differential rotation of lower and upper mantle takes place, as well as upper mantle and lithosphere, in essence, this is equivalent to a flow in the mantle [26], which is likely to be unstable owing to reasons listed above. Instability of a border's dynamic surface originated from different rotational speeds of the covers generates a vortex component of motion and, 
as a consequence, a tendency to form vortex-like whirling of opening zones at the breakup of the megacontinent.

It is believed that the nature of a vortex component of motion when back-arc and inter-arc spreading basins were formed in the west and southwest Pacific margins is connected with subduction of relatively ancient, cold, and heavy lithosphere of Pacific under relatively hot and light lithosphere of Eurasia, as it is in the converging area of Pacific and Eurasian plates. A subduction zone is a dynamic interface where the relative motion of plates is dominanting along with simultaneous compression. Such phenomenon, essentially, may be considered as an analogue of a warm atmospheric front where cold relatively heavy air dives (subducts) under relatively light and hot air. A comparison of subduction with an atmospheric front is not a new idea; it exists in geological literature [27]. An atmospheric front is a dynamic interface between masses with different physical specifications (both a subduction zone and interface between covers). Atmospheric fronts present the exact cause for secondary atmospheric vortexes, arising at flexures of dynamic interfaces. Despite the distinctly different time scales, the physical basis of vortex formation is the same: flexures and dynamic instability of interfaces generate vortex motions both in atmosphere and in mantle in the area of plate converging.

Vortex motions caused the formation of small vortex-like structures, like overlapping spreading centers at the EPR crest, likely to be resulted from instability of flow of matter along the rise's axis. The existence of such flows is postulated based on the analysis of both structural development and interpretation of geophysical fields of oceanic rifts. It is significant that structural patterns like OSCs are discovered not only at fast spreading MOR in the Pacific but at the slow spreading Reykjanes and Kolbeinsey ridges in North Atlantic where the data on a flow of matter along the ridge's axis are very reliable.

\subsection{Interpretation of some geodynamic phenomena with nonlinear medium model}

The idea of both nonlinear geological medium and vortex motions in it allows us to suggest new interpretation of some geodynamic phenomena accompanying the ocean formation, which nature is hard to explain in the context of plate-tectonics' fixed paradigm.

Segmentation of passive continental margins and the oceanic bottom. The segmentation of passive continental margins and the oceanic bottom into sections of different orders has a global importance. It was repeatedly noticed that the configuration of continents (and, accordingly, the ocean) in plan are rounded. Broken stepwise contours connected with varied-order segmentation of passive continental margins and the oceanic bottom seem to be enclosed in smooth, rounded outlines of the oceanic basins. Undoubtedly, there is some in-depth meaning behind this geometrical enclosure. The progress in the study of physical specifications of the Earth's solid covers really resulted in the appearance of such concepts as the enclosure of deformation processes occurred in these covers [28]. The enclosure is generally meant the modification of continuum mechanic model, needed for description of mechanical difference in the crust and lithosphere for different spatial-temporal scales. As indicated above, for the oceanic lithosphere, the enclosure may be observed at a geometrical level.

Comprehensive geophysical researches of the ocean/continent boundaries in some regions of the world-ocean passive margins (for a example, at the South Atlantic) not only confirm similar peculiarity of structural geometry, but also reveal the self-similarity of stepwise configuration for the more detailed scale of researches [29]. The most of continental rifts, which usually are regarded as early evolutional stages of young oceans, are also 
characterized by both broken outlines in plane and separation of isolated structural segments. At that, the most of them demonstrate, in addition to stretching normal to the rift's axis, a slide component that characterize them as pull-apart structures. Together the data on configuration of continental rifts with geometry of the ocean/continent boundaries allow us to conclude that the breakup of Pangaea supercontinent took place along rounded lines, which at zooming occur to be stepwise ones, though they partly inherited suture zones of basement. It should be noted that in the limits of present plate-tectonic paradigm, a question about both enclosure of deformation processes and geometrical enclosure in the ocean formation is not considered at all; researchers are mostly deal with the analysis of structural links between continental rift zones and oceanic ones [30].

The specificity of vortex motions, occurring in unstable medium allows one to throw light on the nature of this phenomenon. Figure 8 presents a comparison of structural patterns of (a) a cyclonic synoptic vortex in the atmosphere, (b) the oceanic basin formed by vortical motion, and (c) the oceanic basin formed according to a plate tectonic model. If the continents' breakup and further evolution of the oceanic basin occur under effect of whirling, the opening line gets rounded in accordance with pattern of the vortex flow. The velocity of combined reciprocating and rotating motion of matter within it varies from its inner part to the outer zone (fig. 8a) This causes an appearance of the shear component in the lithosphere and reasons pull-apart features in continental rifts in the early continental stage of the ocean's opening. The line of initial opening of the ocean (at a later time, passive margins), though retains rounded shapes in general, but is divided into isolated segments, i.e. gets broken, saw-shaped. Geometry of such segmentation is characterized by

(a)
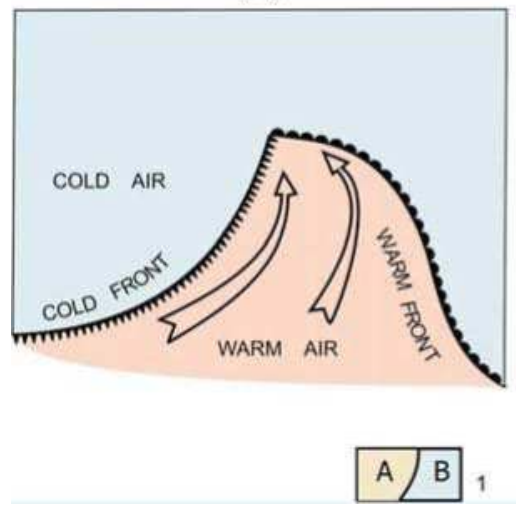

(b)

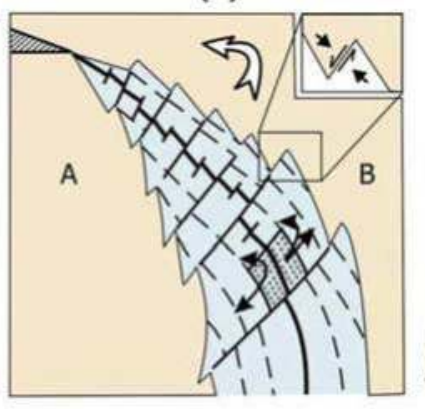

(c)

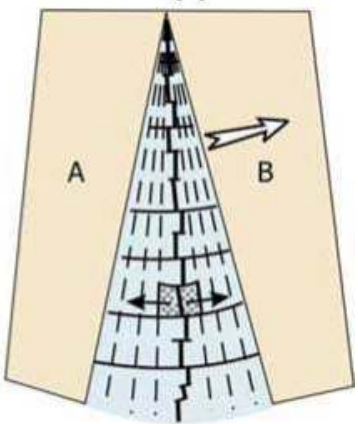

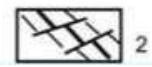
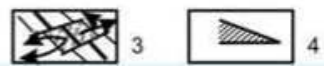

Fig. 8. Structural patterns of (a) a cyclonic synoptic vortex in the atmosphere, simplified after [40], (b) the oceanic basin formed by vortical movements, and (c) the oceanic basin formed according to a plate tectonic model. The arrows in Fig. 8a indicate the direction of warm air migration, while the arrows in Figs. $8 \mathrm{~b}$ and $8 \mathrm{c}$ indicate the displacement of continental plate $B$ relative to continental plate A. (1) Continental crust (A) and oceanic crust (B); (2) isochrons of the oceanic crust and transform faults; the heavy line is the spreading axis; (3) elementary bodies of plates and directions of their motion; (4) area of compression. The inset shows the orientation of stress at the boundary between the oceanic and the continental lithosphere during the opening of the oceanic basin. 
self-similarity due to above-mentioned fractal properties of the medium. Moreover the change of velocities inside the vortex flow stimulates generation of dynamic separation surfaces within it and, accordingly, vortical structures lesser in size, which can also influence the configuration of the opening line.

At the stage of utter breakup of continental crust and of formation of spreading zones, vortical movements produce rotatory motions of varied volumes of matter around independent axes, which initiates twirling stresses in the new-formed thin oceanic lithosphere that is likely to be a major cause for origine of varied in rank structural echeloned segmentation.

Thus, both the geometrical roundness of continental contours and different in order segmentation of the oceanic bottom are connected with the specificity of vortical movements. But if the origin of the first phenomenon is apparently described by motion of viscous fluid (vortex flow), the nature of the second one in the best way should be interpreted on the basis of models of continuum mechanics (response of the breakable and elastic lithosphere to effect of vortex flows).

Tectonic delamination of the lithosphere. It was found that this phenomenon is widespread, and it is widely covered in the literature, including monographs [31]. As illustrated in many works, horizontal or close to horizontal displacements of deep or subsurface rock masses lay in the basis of origin of this phenomenon that results in the formation of roughly horizontal boundaries in the both crust and lithosphere, and tectonic stacking as well. From the analysis of high-tech seismic profiling results, numerous inclined reflectors were recognized in the oceanic crust. This fact, as well as results of both dredging and deep-water drilling, serves as the basis of new ideas of infrastructure and dynamics of the upper oceanic lithosphere. At the same time the tectonic nature of interpreted horizontal surfaces is doubtless. It was mentioned that tectonic delamination is peculiar not only to the modern oceanic lithosphere, but to ancient one as evidenced by structure of ophiolite complexes of different ages.

The authors of works devoted to this phenomenon note that a concept of the lithosphere's delamination is based on the data confirming a wide distribution of shear dislocations. It follows from the model of vortical movements that if a vortex flow affects the lithosphere's bottom, shear dislocations should occur there (subject to an upright position of the vortex axis, and, correspondingly, a horizontal orientation of the flow surface). Relatively independent rotation of varied in size masses in such flow should contribute to roughly horizontal displacements of some blocks of the crust and lithosphere and, hence, form subhorizontal interfaces of tectonic nature. Moreover, rotation of varied in rank blocks of the crust appears independently one of another, around different axes, which inevitably result in the compression stress even in the crest zone of the mid-oceanic ridges. This was confirmed by comprehensive seismic observations in the axis of the Mid Atlantic Ridge where rupturing deformation reasoned by compression was revealed[32].

It is needless to say that, all presented above is only a qualitative scheme of origin of the oceanic lithosphere's delamination, but produces a basis for interpretation of the available data, as well as for carrying out quantitative assessment.

Fold deformations within passive margins. As follows from the model of the oceanic opening under the effect of vortical movements (fig. $8 \mathrm{~b}$ ), geodynamic settings vary along the interface of continental plates. As the whirl develops, the compression component rises; the stronger is twirl, the stronger becomes compression that should be reflected in the structure of the Earth's crust. Inded, at the closure of strongly whirled vortical structures framing 
Easter and Juan Fernández microplates at the EPR crest, underwater ridges resulted from compression are discovered [33]. The similar in nature of the crust deformations microplates of Gorda in the Pacific appear as both flexures and shortening of banded magnetic anomalies, and pattern of seismic activity [34]. Of special interest are fold deformations within passive continental margins, which don't correspond with widespread plate-tectonic evolutionary models, but can be quite well explained with the vortical motion.

Passive margins reflect the transfer from the ocean to the continent inside the lithosphere plate; they result from the continent's fragmentation during continental rifting, then, move aside of divergent boundaries, and with time change into regions with significant sag of the crust and deposition of a thick sedimentary stratum. They are not boundaries of plates, their name itself reflects their relatively tectonic inactivity: intensive sagging is dominant and other tectonic movements are excluded.

This roughly describes a plate-tectonic point of view on the origin and structure of these margins, whish is recognized by the most of researchers. However, intensive geophysical investigations carried out within such areas during the latest decades due to high oil-andgas prospects revealed signs of fold deformations in some regions of passive margins. We consider them at the example of junction zones of passive type in the well-studied Norwegian-Greenland Basin [35; 36], which evolution from the position of vortical movements was considered above.

In contrary to the earlier ideas of the tectonic stability of the regions surrounding the basin, clear evidences of tectonic motions both vertical and horizontal during the Neogene time were revealed within them. Distinct signs of compression deformations of sedimentary stratum were discovered within the Atlantic margins of Norway, the Faroes, British and Shetland Islands, and along the southwestern margins of the Barents Sea; as well as at the eastern margins of Greenland (fig.9). In the middle of the Norway margins, they appear as local elevations framed by overfaults. Some of them are reflected in the bottom topography. Along the eastern segment of Jan Mayen Transform Fault, these elevations are characterized by clear echeloned pattern. The time of deformations was defined as Early Miocene to Later Eocene using analysis of seismic sections and drilling data. Some of positive folded structures were formed as result of both deformation stages.

Comprehensive three-dimensional seismic-stratigraphic researches of one of these elevations within passive margins of Norway brought out clearly that it was formed under tectonic compression normal (or roughly normal) to the rifting axis and spreading axis afterwards. The age of compression was defined: they were generated simultaneously or synchronously with the continental breakup at about $55 \mathrm{Ma}$. It is the researchers' opinion that folded structures could be result of both compression and shift. It is obvious that the initiation of this pair of forces fits with the idea of vortical nature of the spreading basin: at the initial stage of its opening, both components, compression and shift, appear in the area of the strongest whirling of vortical structure, which is being observed in reality.

In the eastern Greenland, folds and overfaults are found in the northern Jamson Land. They are of later Miocene age. Resent researches have shown that the folds have a wavelength of $5-10 \mathrm{~km}$ with total compression estimated as about $1 \%$. This value agrees to the estimation of compression based on the evolutionary analysis of positive morphostructures at the western slope of Norway. Moreover, the continuation of the Greenlandian Transform Fault to the limits of the eastern Greenland is also accompanied by compression and folding. 


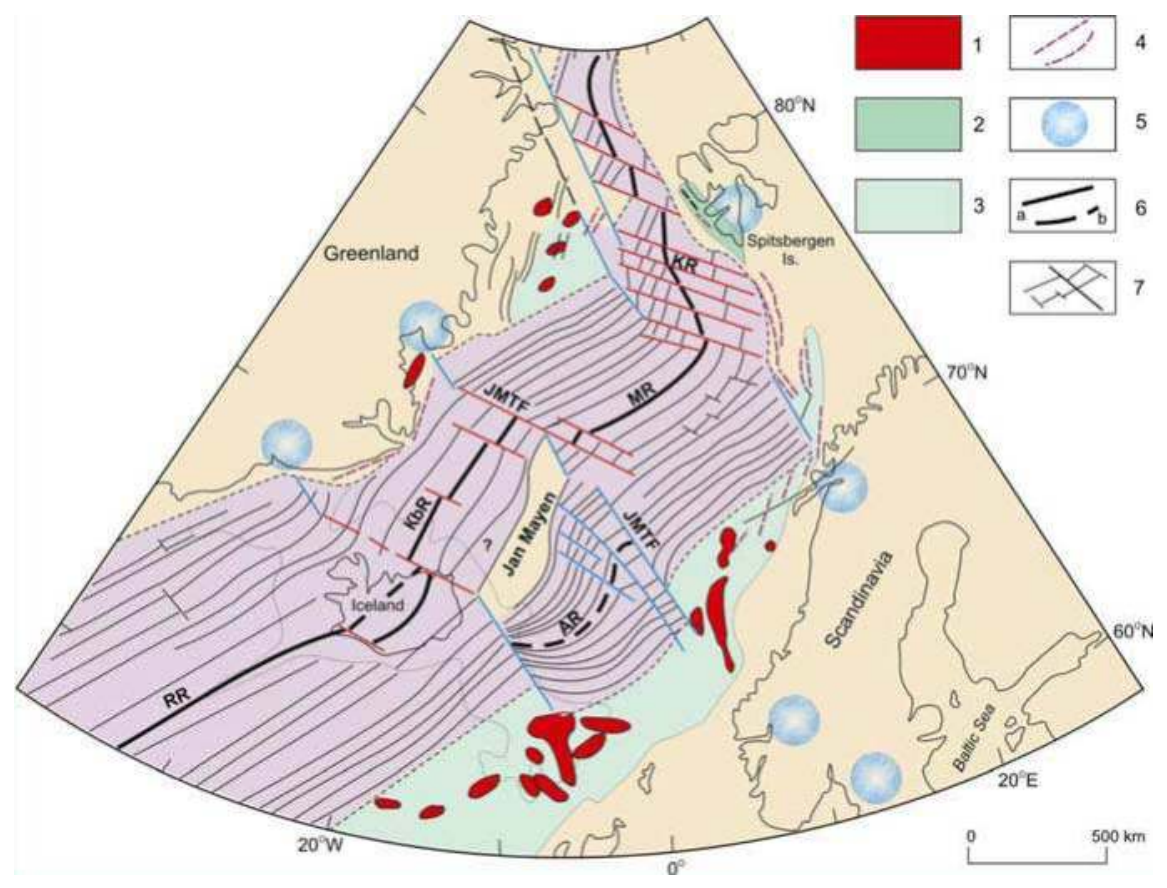

Fig. 9. Regions of passive margins of the Norwegian-Greenland Basin, where the folding of the sedimentary cover and the Neogene uplift are documented. Passive margins and the adjacent continental regions: (1) local uplifts formed by compression; (2) foldbelt west of Spitsbergen; (3) areas of the Late Cretaceous and Paleogene crustal extension; (4) shelf areas; (5) areas of intense Neogene uplifting. The ocean floor: (6) axes of (a) active and (b) extinct spreading; (7) axes of magnetic anomalies. (EJMFZ) East Jan Mayen Fracture Zone, (WJMFZ) West Jan Mayen Fracture Zone, (GFZ) Greenland Fracture Zone, (DSFZ) Denmark Strait Fracture Zone, (KnR) Knipovich Ridge, (MR) Mona Ridge, (KR) Kolbeinsey Ridge, (AR) Aegir Ridge, (RR) Reykjanes Ridge, modified after [16]

Within the southwest margins of the Barents Sea, tree major segments with different paleogeodynamic setting are known (from the south to the north): shift dislocations along the Senja Fault; oblique compression within margins of the Sørvestnaget Basin; and compression and shift along the zone of Hornsund faults. Such a change of geodynamic settings along the boundary of continental breakup can be connected with a vortical model of opening of this oceanic part.

The discovery and researching of domes in the sedimentary cover caused by tectonic compression in passive margins stimulated their further intensive study, and, in particular, works devoted to the comparison of these structures and ones long known within the ocean/continent junction zones of active type were carried out. One of such works presents the comparison of corresponding structures within Voring Plateau (Norway margins) and the northern Honshu Island (Japan) [37]. It was mentioned that tectonic evolution of so different global geostructures as passive margins of Norway and the active volcanic arc of Honshu (Japan) has a common feature, which consists in the fact that in both regions a long stretching period gave place to strong compression that caused generation of dome-like elevations. 
It is obvious that although a problem of fold deformations of passive margins has aroused not a long time ago (because they have currently been found) it is of great importance from the position of both theoretic geotectonics and oil-and-gas prospecting. An applied aspect of this problem is evident and many specialists in oil-and-gas prospecting have realized it. In particular, disappointing results of prospecting at some districts of the Barents Sea are indeed connected with rising and erosion of deposits caused by compression.

Possible nature of mantle plumes. In a very nonequilibrium nonlinear medium of the Earth's solid covers, the various dynamically unstable interfaces can appear during the Earth's evolution. Correspondingly, this originates vortical movements of varied intensity. If we continue the analogy with processes in the Earth's outer covers, within its inner covers exceptionally strong (taking into account the medium properties) vortexes, tornados or twisters, can appear. In reality, among the Earth's lithosphere plates, there are small ones with angular velocity of rotation an order (or more) higher than the one of other plates. It can be suggested that they are rotated by intense vortical movements. Such fast-rotating (at a geological scale) plates are mostly restricted to weak permeable zones in the both crust and lithosphere where mantle masses with different physical characteristics interact similarly to the ones in the subduction zones. The formation of a fast-rotating vortex is most probable in such zones. A similar vortex in the atmosphere (tornado) is characterized by a strong vertical flow, which carries the matter from the bottom upwards. If such mechanism works in the inner covers, a narrow column of deep, hot, and softened matter with low seismic speeds should be found under fast-rotating plates. We consider some of the most striking examples from this standpoint.

Two typical hot spots, which origin by a common opinion is connected with upward mantle flow, are Iceland and Easter Island. Both of them are drawn towards tectonic junctions: Iceland is located at the intersection of the MOR's spreading zone and a transverse fault zone, and Easter Island is located not far off the triple junction of EPR and Chilean Rise. Both regions are characterized by the presence of very fast-rotating microplates. The Jan Mayen Microplate located north of Iceland during Palaeocene-late Miocene had a speed of rotation about 3 degree/Ma and the Easter Microplate is rotating still faster, about 15 degree/Ma. Cross-sections of the both crust and mantle up to 2,000 km were built for both regions based on the data of seismic tomography and varied in direction (fig.10). Beneath Iceland, a quite narrow roughly low-velocity vertical channel reaching the boundary of the lower mantle was revealed. Beneath Easter Island a channel with lower seismic velocities was also found in the middle and lower layers of the upper mantle (although it is not so clear as the one beneath Iceland). Both sections show distinct delamination of the upper mantle: in a vertical section, horizons with different seismic velocities are clearly distinguished. From the concept of vortical movements, it is known that such conditions are especially favorable for originating the fast rotating vortexes. We can notice that to explain magmatism of the Kamchatka region, as well as of some other regions with intraplate magmatism, a similar hypothesis was offered, suggesting a supposition of both, formation of strong vortical movements in the asthenosphere and «fluid-magmatic tornado» effecting the lithosphere and cause generation of hot spots [38].

The most of them are restricted to passive continental margins (for example, Deccan, Karoo, and Ferrar traps adjacent to the Indian Ocean, Etendeka, Parana, and Benue Trough adjacent to the Atlantic), in this connection it was repeatedly suggested that a causal relationship between plumes and continental breakup should exist. At the stage of continental breakup, 

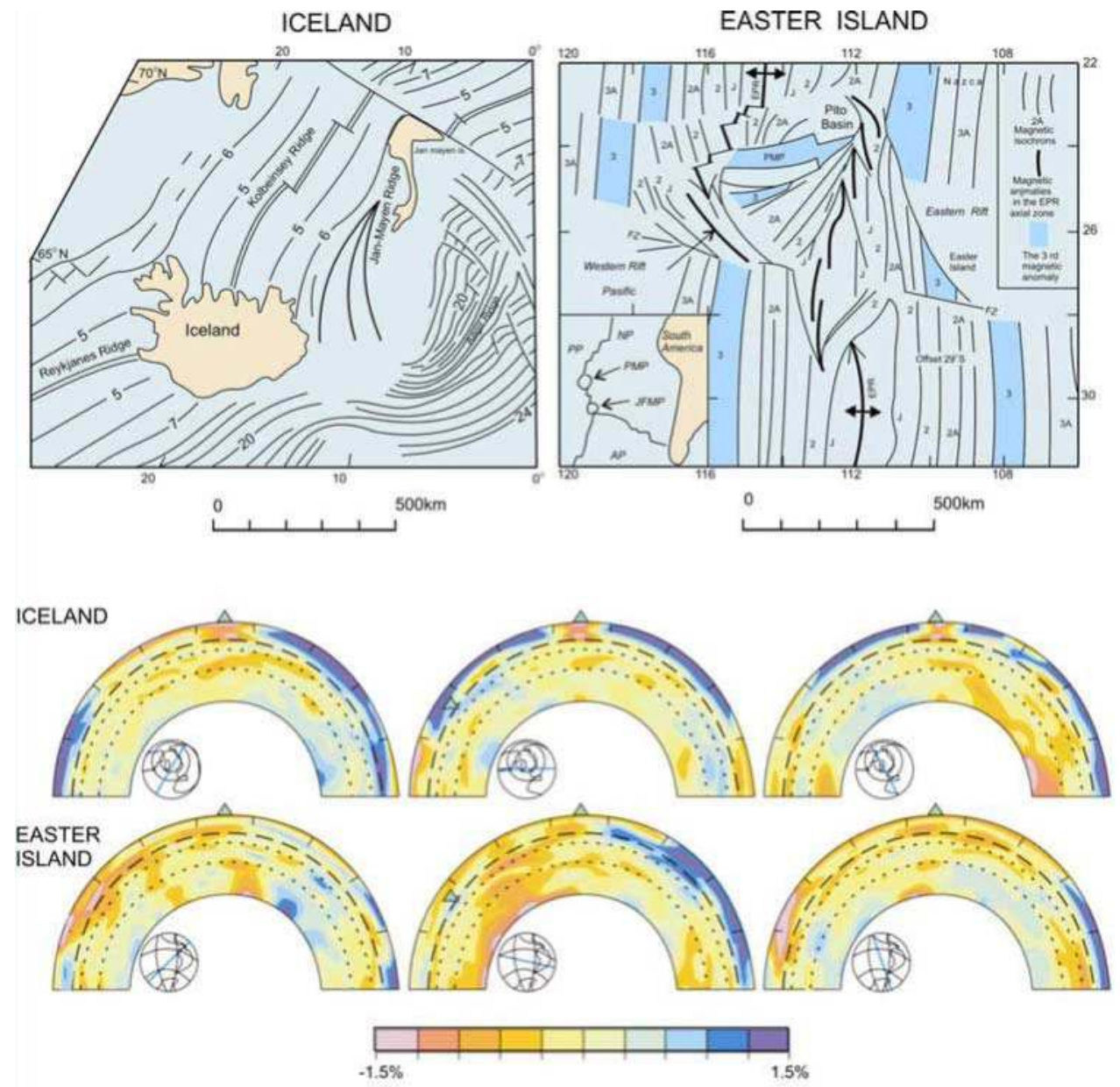

Fig. 10. Structural schemes of the Jan Mayen microplate, northeast of Iceland, and the Easter microplate at the crest of East Pacific Rise (upper panels) and tomographic sections along three profiles across these regions (lower panel), after the data reported in [41]. Axes of magnetic anomalies and their numbers are shown in the structural schemes. Location of the Easter and Juan Fernandez microplates is shown in the insets (see the upper right panel). (EPR) East Pacific Rise, (CR) Chile Rise, (NP) Nazca plate, (PP) Pacific plate, (AP) Antarctic plate, (PMP) Pacific microplate, (JFMP) Juan Fernandez microplate. Shades of gray show increased velocities of seismic wave propagation relative to the average (\%): darker is faster and lighter is slower. The heavy dashed line in cross sections represents the boundary at a depth of $670 \mathrm{~km}$, while the thin dashed lines represent the boundaries at depths of $1,000 \mathrm{~km}$ and $1,700 \mathrm{~km}$.

the conditions favorable for generation of above considered fast-rotating vortexes could exist, and, correspondingly, for channels ascending deep matter in specific places of the breakup line. This line, as considered above, has always a saw-toothed shape, and at that, a 
stress field in the opposite parts of 'tooth' varies due to a specific character of vertical movements. To the explanation comes from Figure $8 \mathrm{~b}$, where the inset shows the orientation of stress vectors for one tooth at the moment of continental breakup. It is not difficult to see that a vortical component of the motion of the continental plate B relatively the plate A results in the generation of a dynamic subsurface where two forces are dominant, shift and compression. This is similar to dynamics of a subduction zone where conditions for the origin of strong vortexes exist. Turning to actual data we can see that at least some of the above mentioned trap provinces (for example, Etendeka and Benue Trough) are indeed restricted to those ledges of the African coastline where at the breakup stage similar geodynamic settings are known.

It is to be studied whether such hypothesis is correct to explain the nature of other hot sports and plumes. It is known that the mantle zones with lower velocities do not always correspond to them. However, a fast-rotating vortex is relatively short living thing (subject to the conditions of the medium where it forms). With this fact in mind we can suggest that the appearance of zones with lower velocities is dominantly governed by the evolutionary stage of one or other region of intraplate volcanism development.

\section{Conclusion}

Thus, the basis for the conception of nonlinear unstable geologic medium is an idea of opposite entropy flows influencing the energy balance of an open system. The use of the concept for geodynamic interpretations is not limited with the above shown examples. In particular, the origin of elastic vibrations in the Earth's crust, which is traditionally connected with earthquakes resulted from mechanical breaking of rocks is considered from the same standpoint. A thermodynamic scheme of rocks' destruction results in different interpretation of processes causing explosive-like energy output in the earthquake epicenter. In essence, we are dealing with a complete change of paradigm of seismology [9]. Other examples demonstrated self-organization of geological medium at various scales from micro level to mega level accompanied by formation of dissipative structures, i.e. the structures, in which the dissipation of endogenous energy is most efficient [38].

In the outer covers of the Earth's, atmosphere and hydrosphere, wide variety of vortical movements is observed, and they play a leading part in dynamics. The mentioned facts, as well as their interpretation, earnestly demonstrate existence of such motions in the inner solid covers, and they are of great importance in dynamics of these covers too. Suffice it to say that two thirds of the Earth's surface, to be exact - the oceanic lithosphere is formed under the direct impact of vortical movements. This conclusion is of fundamental importance for geotectonics, because it confirms above-mentioned theses about properties of the medium where processes defining the structural face of the Earth's crust take place, and these processes can not be considered as purely mechanical ones. Physical essence of these processes is a subject for special consideration, being beyond the scope of this article, however it is important to emphasize that vortical motions can be realized in a very nonequilibrium and nonlinear medium only. For one's turn, this implies that the epoch of domination of a plate tectonic paradigm comes to an end: its basis is mechanics of continuum, whereas the foundation of the future conception is nonlinear thermodynamics of a very nonequilibrium medium. Today's question is the revaluation of lithosphere as solid and fragile covers, because it is in inconsistent with ideas of medium fluidity and rankinvariant vortical movements in solid covers. Complex of lithospheric structures resulted 
from vortical movements should be considered in the frames of vortical tectonics, replacing new global tectonics. An additional illustration of this is the universality of vortical and spiral structures in micro-, meso-, and mega-world (spiral molecules, vortexes of both atmosphere and the ocean, vortical and spiral galaxies). The basis for a new geodynamic paradigm being formed at present is vortical tectonics, self-organization processes in nonlinear nonequilibrium mediums, and formation of fractal structures of lithosphere.

In summary it may be said that the switch to ideas of a nonlinear medium to explain the nature of most lithosphere structures is a general trend of geodynamics. Nowadays, the issue of the day and prerequisite to successful development is to work out and to start using the completely new (in comparison with fixed plate-tectonics' notion) method of resolving specific, practical problems.

\section{References}

[1] Prigozhin, I. R. Philosophy of Instability, Philosophic matters 1991, 6, 46-57.

[2] Nikolis G. and Prigozhin, I. R. Self-Organization In the Nonequilibrium Systems. From Dissipative Structures Through Jitter To Order. Nauka: Mir, 1979; p 250 [in Russian].

[3] Haken H. Synergy. Mir: Moscow, 1980; p 185 [in Russian].

[4] Breakthrough to Synergy. Forward to the Third Millennium. Nauka: Moscow, 2002; p 478 [in Russian].

[5] Sadovsky M. A. Self-Similarity of Geodynamic Processes. Herald of the Academy of Sciences of the USSR, 1986, 8, 3-11 [in Russian].

[6] Keilis-Borok V.I. Introduction: Non-linear systems in the problem of earthquake preduction. Physics of the Earth and Planet. Interiors, 1990, 61, 1-7.

[7] Nikolaev A. V. Development of Methods of Nonlinear Geophysics. e-zine Herald of the Academy of Sciences, 2002, 1, 20. Problems of Geophysics of the 21 ${ }^{\text {st }}$ Century. Vol. 1. Nauka: Moscow, 2003; p 311.

[8] Sharov, V. I. Tectonic Earthquake As a Nonequilibrium Thermodynamic Process of Rock Destruction, Izv. Ross. Akad. Nauk. Fiz. Zemli, 1992, 5; pp121-127.

[9] Sharov, V. I. Study of Seismic Delamination of the Earth on the Threshold of the 21 st Century. Exploration and Conservation of Mineral Resources, 1998, 2; pp2-4 [in Russian].

[10] Barenblatt, G.I.; Zhivago, A.V.; Neprochnov, Yu.P.; Ostrovsky, A.A. Fractal Dimension: Quantitative Characteristic of Ocean Floor Topography. Okeanologiya, 1984, 24(6), 924-928.

[11] Malinverno, A. Fractals and Ocean floor topography: A review and a model. In: Fractals in the Earth Science. Plenum Press: New York, 1995; pp107-129.

[12] Nikora, V.I. Fractal Dimension As a Quantitative Characteristic of Plain Geometry of Channels. In: Dynamics and Thermodynamics of Rivers, Reservoir, and Marginal Seas: 3rd All-Union Conference. Abstracts. Nauka: Moscow,1989, 1, pp $46-47$ [in Russian].

[13] Chelidze, T.A. Generalized Fractal Law of Seismicity. Proc. of Acad. of Scie. of the USSR. 1990, 314 (5), pp 1104-1105.

[14] Turcotte D.C. Fractals in petrology. Lithos. 2002. 65.pp. 261-271.

[15] Sornet, D. and Pisarenko, V. Fractal Plate Tectonics. Geoph. Res. Letters, 2003, 30 (3):doi10.1029/2002GLO15043 
[16] Armijo, R., Meyer, B., Navarro, S. et al. Asymmetric Slip Partitioning in the Sea of Marmara Pull-Apart: A Clue to Propagation Processes of the North Anatolian Fault? Terra Nova, 2002, 14 (2), pp 80-86.

[17] Okay, A.I., Kashlar-Ozcan, A., Imren, C., Boztepe-Guney, A., Demirbag, E., Kuscu, I. Active Faults and Evolving Strike-Slip Basins in the Marmara Sea, Northwest Turkey: a Multichannel Seismic Reflection Study. Tectonophysics, 2000, 321, pp189218.

[18] Aydin, A. and Nur, A. Evolution of Pull-Apart Basins and Their Scale Independence. Tectonics, 1982, 1, pp 91-105.

[19] Sanders, C.O. and Slemmons, D.B. Recent Crustal Movements in the Central Sierra Nevada-Walker Lane Region of California - Nevada. Part III, The Olinghouse fault zone. Tectonophysics, 1979, 52, pp 585-597.

[20] Dubinin, E. P. and Ushakov, S. A. Oceanic Rifting. GEOS: Moscow, 2001, 293 [in Russian].

[21] Mirlin, E. G. Fractal Formation of Structure at Different Stages of Oceanic Lithosphere Formation: Prerequisites, Examples, and Problems. Okeanologiya, 2006, 46 (1), pp 123-133.

[22] Mirlin, E. G. The Problem of Vortical Movements in the Solid Earth and Their Role in Geotectonics. Geotektonika, 2006, 4, pp 282-296.

[23] Mirlin, E. G. and Zorina, Yu. G. The Openning of Oceanic and Marginal Spreading Basins: Contrastive Analysis. Geotektonika, 1992, 1, pp21-33.

[24] Lebran, J-F., Lamarc, G., Collot, J-Y. Subduction Initiation At a Strike-Slip Boundary: The Cenozoic Pacific-Australian Plate Boundary, South of New Zealand. Jour. of Geoph. Res., 2003, 108, pp 15-1 - 15-8.

[25] Okino, K. and Fujioka, K. The Central Basin Spreading Center in the Phillipine Sea: Structure of an Exinct Spreading Center and Implications for Marginal Basin Formation. Jour. of Geophys. Res., 2003, 108, pp EPM 5-1 - 5-18.

[26] Khain, V. E. and Lomize, M. G. Geotectonics with Principles of Geodynamics. UniversitetKnizhnyi Dom: Moscow, 2005, 560 p [in Russian].

[27] Vortices in Geological Processes. Kamchatsky State Pedagogic Univ., PetropavlovskKamchatsky, 2004; 297p [in Russian].

[28] Gol'din, S. V. Physics of the Living Earth. In: Problems of Geophysics of the 21st Century. Nauka: Moscow, 2003; 310 p [in Russian].

[29] Mirlin, E. G. , Kononov, M. V., Sushchevskaya, N. M. Vortical Spreading Systems in the Lithosphere and Upper Mantle. Dokl. Earth Sci., 2005, 401 A (3), pp 370-373.

[30] Kaz'min, V. G. and Borisova, I. A. Structural Relationships between Continental and Atlantic-Type Oceanic Rift Zones. Geotektonika, 1992, 27 (6), pp 80-98.

[31] Peive, A. A. Ruzhentsev, S. V. Sokolov, S. D., et al. Tectonic Delamination of the Lithosphere. Nauka: Moscow, 1980, 215 p [in Russian].

[32] Raznitsin, Yu. N. Tectonic Delamination of the Lithosphere in Young Oceans and Paleobasins. Nauka: Moscow, 2004, 270 p [in Russian].

[33] Larson R.L., Searl R.C., Kleinrock M.C., Shouten H., Bird R.T., Naar D.F., Reisby R.I., Hooft E.E., Lasthiotakis H. Roller-bearing tectonic evolution of the Juan Fernandez microplate. Nature, 1992, 356, pp 571-576.

[34] Wilson, D.S. Deformation of the So-Called Gorda Plate. J. Geophys. Res., 1989, 94(B3), pp 3065-3075. 
[35] Boldreel, L.O. and Andersen, M.S. Tertiary Compressional Structures on the FaroeRockall Plateau in Relation to Northeast Atlantic Ridge-Push and Alpine Foreland Stresses. Tectonophysics, 1998, 300, pp 13-28.

[36] Lundin, E. and Dore, A.G. Mid-Cenozoic Post-Breakup Deformation in the «Passive» Margins Bordering the Norvegian-Greenland Sea. Marine and Petrol. Geol., 2002, 19, pp 79-93.

[37] Mjelde, R., Iwasaki, T., Shimamura, H., Kanazawa, T.,.Kodaira, S., Raum, T., Shiobara, H. Spatial Relationship Between Recent Compressional Structures and Older HighVelocity Crustal Structures; Examples from the Voring Margin, NE Atlantic, and Northern Honshu, Japan. J. of Geodynamics, 2003, 36, pp 537-562.

[38] Goryainov, P. M. and Ivanyuk, G. Yu. Self-Organization of Mineral Systems. Synergetic Principles of Geological Studies. GEOS: Moscow, 2001, 312 p [in Russian].

[39] Scotese, C.R. Paleomap Project. http:/ / www.scotese.com 2002.

[40] Soldatenko, S. A. Synoptic Vortices in the Atmosphere and Ocean. Soros. Obrazov. Zh., $1989,2,78-84$.

[41] Ritsema, J. and Allen, R.M. The Elusive Mantle Plume. Earth Planet. Sci. Lett., 2003, 207, pp1-12. 


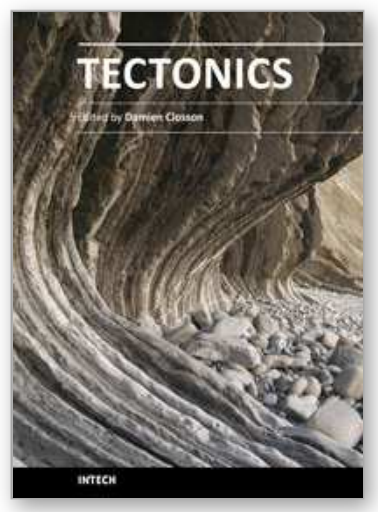

\author{
Tectonics \\ Edited by Dr. Damien Closson
}

ISBN 978-953-307-545-7

Hard cover, 358 pages

Publisher InTech

Published online 28, February, 2011

Published in print edition February, 2011

The term tectonics refers to the study dealing with the forces and displacements that have operated to create structures within the lithosphere. The deformations affecting the Earth's crust are result of the release and the redistribution of energy from Earth's core. The concept of plate tectonics is the chief working principle.

Tectonics has application to lunar and planetary studies, whether or not those bodies have active tectonic plate systems. Petroleum and mineral prospecting uses this branch of knowledge as guide. The present book is restricted to the structure and evolution of the terrestrial lithosphere with dominant emphasis on the continents. Thirteen original scientific contributions highlight most recent developments in seven relevant domains: Gondwana history, the tectonics of Europe and the Near East; the tectonics of Siberia; the tectonics of China and its neighbourhood; advanced concepts on plate tectonics are discussed in two articles; in the frame of neotectonics, two investigation techniques are examined; finally, the relation between tectonics and petroleum researches is illustrated in one chapter.

\title{
How to reference
}

In order to correctly reference this scholarly work, feel free to copy and paste the following:

E. G. Mirlin (2011). Lithosphere as a Nonlinear System: Geodynamic Consequences, Tectonics, Dr. Damien Closson (Ed.), ISBN: 978-953-307-545-7, InTech, Available from:

$\mathrm{http}: / / \mathrm{www}$.intechopen.com/books/tectonics/lithosphere-as-a-nonlinear-system-geodynamic-consequences

\section{INTECH}

open science | open minds

\section{InTech Europe}

University Campus STeP Ri

Slavka Krautzeka 83/A

51000 Rijeka, Croatia

Phone: +385 (51) 770447

Fax: +385 (51) 686166

www.intechopen.com

\section{InTech China}

Unit 405, Office Block, Hotel Equatorial Shanghai

No.65, Yan An Road (West), Shanghai, 200040, China 中国上海市延安西路65号上海国际贵都大饭店办公楼 405 单元

Phone: +86-21-62489820

Fax: $+86-21-62489821$ 
(C) 2011 The Author(s). Licensee IntechOpen. This chapter is distributed under the terms of the Creative Commons Attribution-NonCommercialShareAlike-3.0 License, which permits use, distribution and reproduction for non-commercial purposes, provided the original is properly cited and derivative works building on this content are distributed under the same license. 